\author{
Gerrit C. Hagenah \\ Jens-Gerd Scharf \\ Alexander Emmert \\ B. Michael Ghadimi \\ Friedrich A. Schöndube \\ Bernhard C. Danner
}

\section{Acute gastrointestinal bleeding due to oesophageal varices: an unusual case of a thoracic spleen}

Accepted: 17 September 2009

Published online: 21 October 2009

(C) The Author(s) 2009. This article is

published with open access at

Springerlink.com to hospital because of a first session of haematemesis and recurrent dyspnoea only days before. Patient's history revealed only 15 years of nicotine abuse and an undefined infection episode 17 years ago.

On admission, clinical examination, vital parameters, chest X-ray and ECG findings were unremarkable. Initial laboratory tests revealed no pathologic coagulation tests, but impaired hemoglobin levels $(12.3 \mathrm{~g} / \mathrm{dl})$.

An oesophagoscopy was performed and revealed varices grade 3 [2]. Nine consecutive ligatures were placed. Furthermore, since there was no history or ultrasonic findings of liver disease, a thoracic CT scan was performed, revealing a large retrocardial mass $(12 \times 12 \times 6 \mathrm{~cm}$, Fig. 1) between the main bronchi displacing the oesophagus.

An endosonography excluded an infiltration of the oesophagus, and a pathological specimen taken by video-assisted thoracoscopy showed a vascularised tumor without malignancy. Meanwhile, an emergency oesophagoscopy was indicated due to another session of haematemesis with need for mass transfusion. In the following days, an anterolateral rightsided thoracotomy with tumor

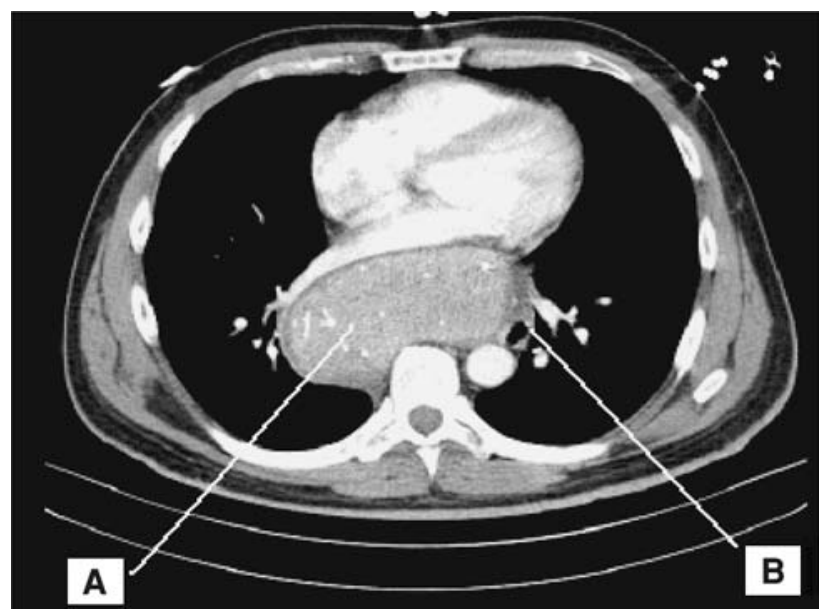

Fig. 1 Thoracic computer tomography with cardiac imaging and retrocardial accessory spleen $(A)$. Oesopageal displacement to the left of the tumor $(B)$

resection followed. The arterial delivery was provided by a number of bronchial arteries of both main bronchi. The cause of the paraoesophageal plexus varices was more likely the tumorous venous drainage than the compression by the tumour itself (Fig. 2).

Histological examination and further immunohistochemical differentiation of the resected mass revealed an ectopic accessory spleen confirmed by a second, independent pathologist.

A deep venous thrombosis occurred preoperatively promoted by lack of anticoagulation despite immobilization. Because postoperatively the thrombosis reached the pelvic vessels, a venous thrombectomy was also performed. The postoperative oesophagoscopy showed varices decreased to grade 2, and anticoagulation with coumadin was started.

\section{Discussion}

The most common posterior mediastinal tumors are of nerve-cell origin [3]. Other mediastinal masses can derive from lymphomas, bronchogenic malignancies or congenital arteriovenous malformation [4].

Ectopic splenic tissue has been described in the form of accessory spleens or splenosis [5]. Thoracic splenosis is defined as autoimplantation of splenic tissue in the thoracic cavity after splenic injury [6]. Our patient had no history of injury, and absent a diaphragmic injury, a thoracic splenosis was not assumed. An accessory spleen is present in $10-30 \%$ of individuals [7] with the most common areas being the splenic hilus or the tail of the pancreas [5]. This case of a retrocardial accessory spleen as a cause of variceal bleeding is unique, and no reports exist of ectopic accessory spleen as in this case. 


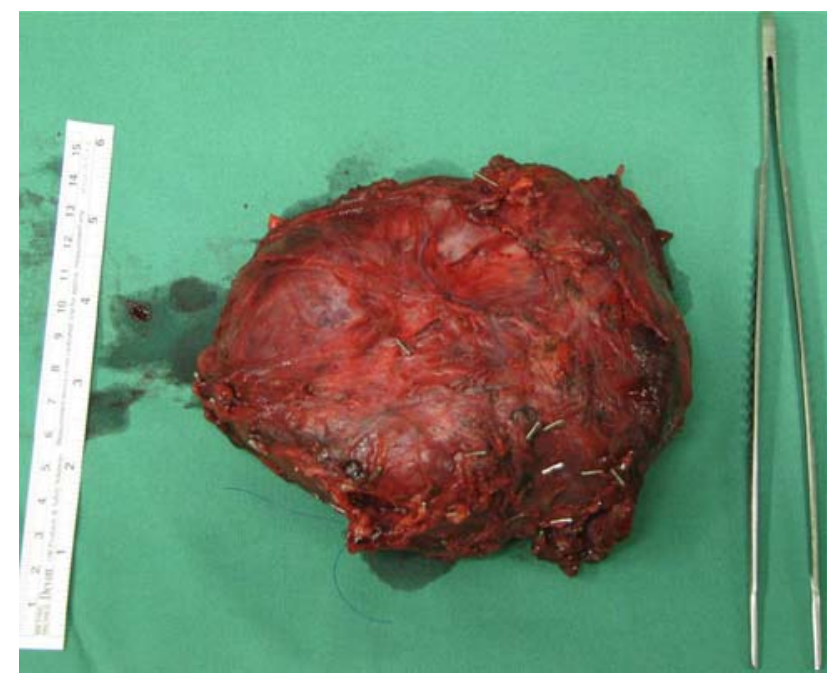

Fig. 2 Macroscopy after resection. At thoracic surgery the posterior mediastinal mass was $12 \times 12 \times 6 \mathrm{~cm}$ in diameter. Macroscopic pathology was characterised by large vessels (see clips)

Removal of a specimen by videoassisted thoracoscopy could have been sufficient to establish diagnosis. A CT-guided biopsy was avoided due to a higher complication rate; a mediastinoscopy seemed inappropriate for successful biopsy. A further possibility for removing small samples could have been an endosonography-guided biopsy.

In conclusion, in cases of severe variceal bleeding without any liver disease, compression due to posterior mediastinal tumours should be considered. In this rare case, a retrocardial accessory spleen was diagnosed.

Conflict of interest statement The authors declare that they have no conflict of interest.

Open Access This article is distributed under the terms of the Creative Commons Attribution Noncommercial License which permits any noncommercial use, distribution, and reproduction in any medium,
4. Ching AS, Chan PN, Cheung H, Chan YL, Metreweli C (2000) CT and DSA appearances of a ruptured congenital arteriovenous malformation of the posterior mediastinal aorta. Br J Radiol 73:1320-1322

5. MacDonald JK, Wilke RA, Jacobs WE (2000) Accessory spleens in the thoracic and abdominal cavities after a relapse of idiopathic thrombocytopenic purpura: a case report. J Nucl Med Technol 28:49-51

6. Khan AM, Manzoor K, Gordon D, Berman A (2008) Thoracic splenosis: a diagnosis by history and imaging. Respirology 13:481-483

7. Vural M, Kacar S, Kosar U, Altin L (1999) Symptomatic wandering accessory spleen in the pelvis: sonographic findings. J Clin Ultrasound 27:534-536

\section{G. C. Hagenah (-)}

Department of Nephrology and Rheumatology, Georg-August University

provided the original author(s) and source are credited.

of Goettingen Medical School, Robert-Koch Str. 40, 37075 Göttingen, Germany

e-mail: gerrit.hagenah@freenet.de

Tel.: +49-551-3991374

Fax: +49-551-3910285

\section{References}

1. Lee YC, Wang HP, Wu MS, Yang CS, Chang YT, Lin JT (2003) Urgent bedside endoscopy for clinically significant upper gastrointestinal hemorrhage after admission to the intensive care unit. Intensive Care Med 29:1723-1728

2. Pungpapong S, Keaveny A, Raimondo M, Dickson R, Woodward T, Harnois D, Wallace M (2007) Accuracy and interobserver agreement of small-caliber vs. conventional esophagogastroduodenoscopy for evaluating esophageal varices. Endoscopy 39:673-680

3. Ketata W, Msaad S, Kwass H, Gargouri I, Gheriani MM, Gouiaa N, Dabbech C, Boudawara T, Ayoub A (2009) Thoracic extramedullary hematopoiesis: a diagnosis to not forget in a patient with posterior mediastinal mass with anemia. Resp Med 2:118-120

\section{J.-G. Scharf}

Department of Gastroenterology and

Endocrinology, Georg-August

University of Goettingen Medical School,

Göttingen, Germany

A. Emmert · F. A. Schöndube .

B. C. Danner

Department of Thoracic and Cardiovascular Surgery, Georg-August University of Goettingen Medical School, Göttingen, Germany

B. M. Ghadimi

Department of General Surgery,

Georg-August University of Goettingen Medical School, Göttingen, Germany 